\title{
ВмJ Global Health Short-term and long-term distributional consequences of prenatal malnutrition and stress: using Ramadan as a natural experiment
}

\author{
Farhan Majid, ${ }^{1}$ Jere Behrman, ${ }^{2}$ Subha Mani ${ }^{3}$
}

\begin{abstract}
To cite: Majid F, Behrman J, Mani S. Short-term and long-term distributional consequences of prenatal malnutrition and stress: using Ramadan as a natural experiment. BMJ Glob Health 2019;4:e001185. doi:10.1136/ bmjgh-2018-001185
\end{abstract}

Handling editor Seye Abimbola

- Additional material is published online only. To view please visit the journal online (http://dx.doi.org/10.1136/ bmjgh-2018-001185).

Received 20 September 2018 Revised 16 January 2019 Accepted 19 January 2019

Check for updates

(C) Author(s) (or their employer(s)) 2019. Re-use permitted under CC BY-NC. No commercial re-use. See rights and permissions. Published by BMJ.

${ }^{1}$ Rice University's Baker Institute for Public Policy, Houston, Texas, USA

${ }^{2}$ Economics, University of Pennsylvania, Philadelphia, Pennsylvania, USA

${ }^{3}$ Economics, Fordham University, New York City, New York, USA

Correspondence to Dr Farhan Majid;

farhan.majid@rice.edu

\section{ABSTRACT}

Introduction Fetal environments play significant roles in determining adult well-being, particularly as they relate to non-communicable diseases and skill formation. We studied gender-specific distributional consequences of fetal environment (in the form of in-utero exposure to Ramadan, the Islamic holy month of fasting), in Indonesia, on birth weights, performance on Raven's Colored Progressive Matrices (CPM), math scores, hours worked and earnings.

Methods We used quantile regressions to conduct a quantitative comparison of distributional consequences, by gender, of full month exposures to Ramadan in-utero on outcomes of interest. Our data included Muslim children and adults measured during rounds 1 and 4 of the Indonesian Family Life Survey. Our main outcome measures were: birth weights-559 observations (females) and 624 (males); Raven's CPM scores-1693 (females) and 1821 (males) for 8-15 year olds; math test scores-1696 (females) and 1825 (males) for 8-15 year olds; hours worked - 3181 (females) and 4599 (males) for 18-65 year olds; earnings-2419 (females) and 4019 (males) for 18-65 year olds.

Results Full month of exposure to Ramadan in-utero led to significant reductions at the $5 \%$ significance level that were concentrated in the bottom halves of the outcome distributions: among 8-15 years, lower scores on Raven's CPM tests for females (mean: $-9.2 \%, 10$ th Q: $-19 \%$, 25th Q: $-19.4 \%$ ) and males (mean: $-5.6 \%, 10$ th Q: $-12.5 \%$ ); lower math scores for females (mean: $-8.6 \%, 25$ th $Q$ : $-15.9 \%$ ) and males (mean: $-8.5 \%, 10$ th Q: $-13.6 \%$ ); among females $18-65$ years, significant reduction in hours worked (mean: $-7.5 \%, 10$ th Q: $-26.3 \%$ ).

Conclusion Events during the fetal period have farreaching consequences for females and males in the lowest (10th and 25th) quantiles of outcome distributions, affecting the 'relatively poor' the most. These results call for caution in interpreting studies on child development that rely on mean comparisons alone.

\section{INTRODUCTION}

Since the seminal work on the fetal origins hypothesis by Barker and colleagues published in the BMJ, a large literature of well over 2000

\section{Key questions}

What is already known?

- More than $99.5 \%$ of the 2000 existing studies testing the fetal origins hypothesis only studied mean relations between measures of the fetal environment and later-life disease and well-being

- A few recent papers have studied the consequences of fetal exposure to Ramadan and find that Ramadan exposure led to lower mean tests scores and labour supplies with mixed evidence on birth weights, but none have studied the distributional effects of Ramadan.

What are the new findings?

- The fetal period has far-reaching consequences for females and males in the lowest (10th and 25th) quantiles of the outcome distributions, affecting the 'relatively poor' the most.

What do the new findings imply?

- Long-term effects of fetal environment are underestimated by examining mean effects alone so caution is required in interpreting studies on child development for the relatively poor that rely on mean comparisons alone.

published studies from multiple disciplines has developed arguing that fetal environments play significant roles in determining adult well-being, particularly as they relate to non-communicable diseases and skill formation. ${ }^{1-18}$ These conclusions are based on mean effects of fetal environments (e.g., in-utero exposure to famines and pandemics). Most of this research focuses on qualitative predictions about whether fetal periods matter in the long run rather than quantitative predictions on how much they matter. ${ }^{19-21}$ Even for papers that examine effect sizes, there have been concerns about the presence of confounding variables. ${ }^{22}{ }^{23}$ Furthermore, if impacts of fetal environments are not uniform along the outcome distributions, the mean effects may 
possibly disguise much larger effects near the bottoms of the outcome distributions. This has important implications for targeting policies for the poorest, where they may be most effective and most needed.

We studied the distributional consequences, which are ignored by mean estimates, of fetal shocks over distinct life stages, using in-utero exposure to Ramadan (the Islamic month of fasting) as a natural experiment. Ramadan is one of the holiest months of the Islamic calendar, lasting 29-30 days. The lunar Islamic calendar does not follow the solar seasons, moving back 11 days every year. Muslims are required to fast during daylight hours for spiritual development-fasts that do not allow any food or liquid (not even water) during daylight hours. Although pregnant women are exempt, current evidence from diverse societies suggests that $70 \%-90 \%$ of pregnant women fast at least some days during Ramadan. ${ }^{1524}{ }^{25}$ Since $75 \%$ of all pregnancies overlap with Ramadan, currently more than 1.2 billion (of 1.6 billion) Muslims globally and 155 million Indonesians were potentially exposed to Ramadan fasting and other stresses in-utero. ${ }^{15}$

The evidence is very limited on impacts of exposure to Ramadan in-utero on health and economic well-being of children. One study found that in-utero Ramadan exposure led to: lower birth weights, live births of fewer males than females in the USA; learning disabilities and negative effects on wealth in Uganda and Iraq. ${ }^{3}$ In Indonesia, a study showed that exposure to Ramadan in-utero led to increased likelihood of developing coronary heart problems and type-2 diabetes during old age. ${ }^{11}$ Another study, by the lead author of this article, found that children exposed to Ramadan in-utero studied fewer hours during elementary school, were more engaged in child labour and scored lower on cognitive and math tests. As adults, the exposed children worked fewer hours and were more likely to be self-employed..$^{15}$ There is mixed evidence on the impact of exposure to Ramadan in-utero on birth weights-with some studies reporting no effects while others reporting small impacts. ${ }^{36}$ These studies, following the larger literature on the fetal origins hypothesis, estimated mean effects.

In this study, we hypothesised that impacts of in-utero Ramadan exposure were not identical across all points in outcome distributions. We hypothesised that these distributional effects over the life course affected birth weights, test scores and adult hours worked and earnings. We also hypothesised that the impacts of in-utero exposure to Ramadan were most severe for those in the lower quantiles of the outcome distributions. Finally, there are significant biological ${ }^{27} 28$ and behavioural ${ }^{29-33}$ differences between males and females that impact their health and life outcomes differentially. Hence, we hypothesised that there were gender differences in these impacts. We used data from the 1993 and 2007 waves of the Indonesian Family Life Survey to investigate the effects of being exposed to Ramadan in-utero on distributions of birth weights, child performance on math and Raven's tests and adult hours worked and earnings.

\section{METHODS}

\section{Study design}

Simple comparisons of outcomes between children whose mothers fasted and those who did not, would not yield unbiased effects of Ramadan, as fasting behaviors are the result of individual and family choices (endogenous) that are likely to be correlated with other unobserved factors such as parental socioeconomic status and preferences for child health that probably have direct impacts on the outcome variables of interest. Hence we estimated "intent-to-treat" effects of in-utero exposure to Ramadan, using a dichotomous variable (exposure) $=1$ if individuals were exposed to a full month of Ramadan in-utero (that is, if Ramadan started and ended any time between individuals' birth dates and their estimated conception dates), 0 otherwise. Similar to other studies we combined information on birth dates with the assumption that the average pregnancy lasts 266 days to estimate dates of conception. Only a few pregnancies go beyond the average of nine months; to account for pregnancies longer than nine months we used an additional control equal 1 if individuals were estimated to be conceived less than 21 days after the end of Ramadan, 0 otherwise. ${ }^{1115}$ To control for non-linearities in age and gender differences in outcomes, all specifications included age, age squared, and gender. Finally, we also controlled for seasonality in birth patterns with birth-month dummies. Our analyses yielded unbiased intent-to-treat effects of in-utero exposure to fasting and related stresses during Ramadan on human capital and labor market outcomes as long as birth timings are orthogonal to Ramadans' occurrences. We tested and showed that in fact this assumption held in our sample by running a series of regressions of cohort size, where the dependent variable is defined as the natural logarithm of the number of people born in a given month on Ramadan exposure for each of the subsamples we use in our analysis (appendix table A1). The regressions for cohort size on Ramadan allowed us to assess the number of individuals in our samples who were exposed to Ramadan versus the numbers who were not exposed. If mothers timed their births to avoid Ramadan, we may have expected to see fewer individuals who were born in Ramadan relative to other months. Similarly, if those exposed to Ramadan in-utero were more likely to die than those not exposed to Ramadan in-utero, we may have expected to see smaller cohort sizes for those exposed to Ramadan. Online supplementary table A1 highlights that there was no difference in sample size by exposure for any of the cohorts we study, ruling out selective birth timing around Ramadanor selective mortality biasing our estimates. For hours worked we studied those who participated in the labor force and for earnings we restricted our sample to those with positive net monthly earnings.

\section{Data}

We used the 1993 and 2007 waves of the Indonesian Family Life Survey (IFLS), a large-scale longitudinal survey (http://www.rand.org/labor/FLS/IFLS.html). 


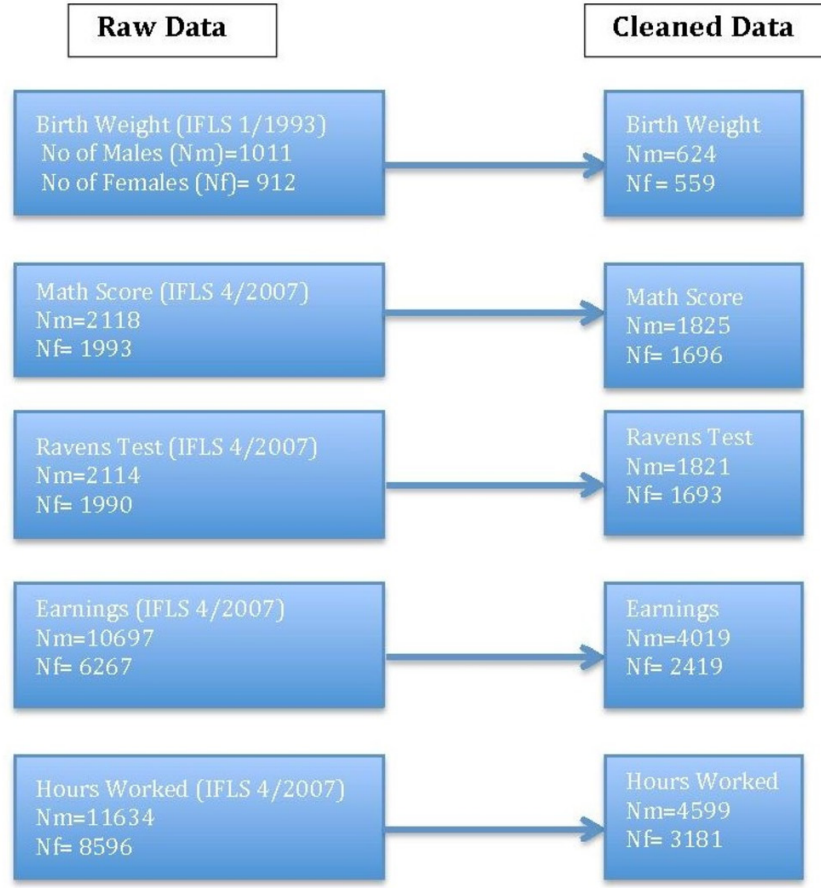

Figure 1 Shows raw data and the cleaned samples used in our analysis.

During IFLS1 in 1993, 7224 households were interviewed, whereas 13535 households were interviewed in 2007 (IFLS4), of which 6596 were original IFLS1 households and the remaining were split-off households. IFLS represented $83 \%$ of the Indonesian population living in 13 of Indonesia's 27 provinces in 1993. A unique feature of the IFLS is low attrition: In IFLS4, the recontact rate of original IFLS1 households was $90.6 \% .{ }^{34}$ The start and end dates of Ramadan were taken from http://www.phys.uu. $\mathrm{nl} /$ vgent/islam/ummalqura.htm and (before 14 March 1937) http://www.al-islam.com/eng. Only very minor discrepancies in dates were found on other sources.

Figure 1 shows raw data and the cleaned samples used in our analysis. We restricted our sample to Muslims who were either fully exposed to Ramadan in-utero or those who were not exposed to Ramadan in-utero at all. The samples for hours worked and earnings were restricted to those aged $18-65$ years in 2007 , for test scores, $8-15$ year olds in 2007, and for birth weights, maternal-recall data were used for those aged 0-6 years in 1993. We included birth weight data from the 1993 IFLS as these children would be 15-21 years in the 2007 IFLS and be part of our adult samples, allowing us to show effects of Ramadan on similar cohorts over long segments of the life course. Birth weights greater than $7 \mathrm{~kg}$ were dropped from the sample (outliers probably due to measurement or recording errors). Results were robust to excluding all those who weighed greater than $5.5 \mathrm{~kg}$. This yielded the following samples for our study: birth weights-424 (females) and 466 (males); Raven's Colored Progressive Matrices (CPM) - 1693 (females) and 1821 (males); math scores-1696 (females) and 1825 (males); hours worked-3181 (females) and 4599 (males); earnings_-2419 (females) and 4019 (males).

\section{Statistical methods}

To estimate distributional consequences of Ramadan exposure in-utero on outcomes, we used conditional quantile regressions. ${ }^{35}$ Quantile regressions estimate treatment effects among individuals at the qth quantile, such as those who are exactly at the bottom 10 th percentile in terms of birth weights, learning/cognition and labour supplies/earnings. For statistical analyses, Stata 14.1 was used. We used the $5 \%$ significance level to determine statistical significance along with two-tailed Wald tests (t-tests).

\section{Patient and public involvement}

No patient and public involvement for my study.

\section{RESULTS}

Tables 1 and 2 present summary statistics on measures of well-being by Ramadan in-utero exposure for Muslim females and males, respectively, at various life-cycle stages. For both tables, the first column gives means, the second column gives coefficients of variation (CV), a measure of dispersion around the mean (ratio of SD to mean) and the next five columns are for the 10th, 25th, 50th (median), 75th and 90th quantiles, respectively.

Girls (boys) aged less than 6 years at the time of the surveys who were exposed averaged birth weights of about $3.08(3.20) \mathrm{kg}$, about $0.03(0.26) \mathrm{kg}$ lower than those not exposed. There was a much smaller difference in the CV between those exposed and those not exposed for girls compared with boys. For girls, there was no clear pattern of disproportionate effects on lower or higher quantiles, but for boys there was evidence of a leftward shift of the entire distribution due to exposure.

Girls 8-15 year old averaged $75 \%(61 \%)$ on Raven's CPM (math) if they were exposed, but those who were not exposed had a higher mean of $78 \%$ (63\%). Boys displayed similar patterns. The CV was higher for test scores for those exposed compared with those not exposed for girls and boys. Exposure to fetal shocks reduced mean skills and it also increased dispersions in skill distributions, driven by asymmetric effects on the bottom quantiles of the test score distributions for girls and boys.

For adults 18-65 years old, mean hours worked in a normal week were 32.5 hours (ln 3.48) and 39.3 hours (ln 3.67) for exposed women and men, respectively, with those not exposed having higher means 35.2 hours (ln 3.56) and 40.9 hours (ln 3.71). The logarithmic form is used because of the right skew in the distributions of the positive values of these variables. Natural logarithms are also more robust to outliers. The parameter estimate for the logged variable approximates the percentage change in the outcome variable. The CV was higher for those women who were exposed (0.22) compared with those not exposed (0.18), but was similar (0.15) for men stratified by their exposure status. Exposure reduced the mean 
Table 1 Summary statistics for Female muslims

\begin{tabular}{|c|c|c|c|c|c|c|c|}
\hline & Mean & CV & Q10 & Q25 & Q50 & Q75 & Q90 \\
\hline \multicolumn{8}{|c|}{ Panel A: Exposed children 0-5 } \\
\hline Birth weight (kgs) & 3.08 & 0.18 & 2.50 & 2.80 & 3.02 & 3.50 & 3.70 \\
\hline Observations & 483 & & & & & & \\
\hline \multicolumn{8}{|c|}{ Panel B: Non-exposed children 0-5 } \\
\hline Birth weight (kgs) & 3.11 & 0.19 & 2.25 & 2.90 & 3.10 & 3.50 & 4.00 \\
\hline Observations & 49 & & & & & & \\
\hline \multicolumn{8}{|c|}{ Panel C: Exposed children 8-15 } \\
\hline Raven's CPM & 0.75 & 0.29 & 0.42 & 0.67 & 0.83 & 0.92 & 1.00 \\
\hline Math score & 0.61 & 0.42 & 0.20 & 0.40 & 0.60 & 0.80 & 1.00 \\
\hline Observations & 1395 & & & & & & \\
\hline \multicolumn{8}{|c|}{ Panel D: Non-exposed children 8-15 } \\
\hline Raven's CPM & 0.78 & 0.26 & 0.50 & 0.67 & 0.83 & 0.92 & 1.00 \\
\hline Math scores & 0.63 & 0.41 & 0.40 & 0.50 & 0.60 & 0.80 & 1.00 \\
\hline Observations & 189 & & & & & & \\
\hline \multicolumn{8}{|c|}{ Panel E: Exposed adults 18-65 } \\
\hline $\begin{array}{l}\text { Hours worked (in } \\
\text { logs) }\end{array}$ & 3.48 & 0.22 & 2.49 & 3.18 & 3.69 & 3.99 & 4.25 \\
\hline Observations & 2581 & & & & & & \\
\hline Earnings (in logs) & 13.00 & 0.09 & 11.51 & 12.30 & 13.12 & 13.82 & 14.40 \\
\hline Observations & 1986 & & & & & & \\
\hline \multicolumn{8}{|c|}{ Panel F: Non-exposed adults $18-65$} \\
\hline $\begin{array}{l}\text { Hours worked (in } \\
\text { logs) }\end{array}$ & 3.56 & 0.18 & 2.64 & 3.33 & 3.69 & 3.99 & 4.25 \\
\hline Observations & 393 & & & & & & \\
\hline Earnings (in logs) & 13.03 & 0.08 & 11.51 & 12.28 & 13.12 & 13.81 & 14.22 \\
\hline Observations & 278 & & & & & & \\
\hline
\end{tabular}

For the test scores, we dropped 3 observations from math scores thatwere missing Raven's CPM. We dropped those who averaged 3 weeks longer than the average pregnancy of 9 months from the samples inthis table. CV refers to coefficient of variation (the ratio of standard deviation to the mean).

and increased the variance of hours worked for women. Most of the dispersion in the hours worked distribution for women was driven by changes in the bottom quantiles of the distribution. Those at the 10th and 25th quantile worked fewer hours on average and registered the largest reduction in hours worked if they were exposed to Ramadan in-utero (see below). For men, only those at the median worked fewer hours if exposed to Ramadan, which was consistent with no difference in the CV. In contrast to hours worked, we did not find a disproportionate effect of exposure on earnings of women; instead we found lower earnings by exposure for women and men on average, with the greatest earnings effect at the 10th quantile for men rather than women in contrast to the effects on hours worked.

The quantile regression effects of being exposed to Ramadan in-utero are presented separately for Muslim females and males in tables 3 and 4, respectively. In these tables, the first column gives the average intentto-treat estimates and the remaining columns give the intent-to-treat estimates of exposure to Ramadan in-utero at the 10th, 25th, 50th (the median), 75th and 90th quantiles, respectively.

\section{Females}

The quantile estimates for birth weights were imprecisely estimated, with the largest effect of $0.320 \mathrm{~kg}$ for those at the 90th quantile. However, for girls 8-15 years old, Raven's CPM was reduced significantly by about $19 \%$ and $19.4 \%$ for those at the 10th and 25th quantiles, respectively. In contrast, top quantiles registered smaller and insignificant effects. For math scores, females exposed to the shock at the 25th quantile scored $15.9 \%$ fewer points, compared with those not exposed. The top 50th-90th quantiles registered smaller and insignificant effects. For adult females, those exposed at the 10th quantile worked $26.3 \%$ fewer hours compared with non-exposed females in this quantile. The higher quantiles registered no significant effects. The mean effect of exposure to Ramadan on hours worked was much smaller for females- $7.5 \%$ 
Table 2 Summary statistics for male Muslims

\begin{tabular}{|c|c|c|c|c|c|c|c|}
\hline & Mean & CV & Q10 & Q25 & Q50 & Q75 & Q90 \\
\hline \multicolumn{8}{|c|}{ Panel A: Exposed children 0-5 } \\
\hline Birth weight (kgs) & 3.20 & 0.21 & 2.50 & 2.90 & 3.10 & 3.50 & 4.00 \\
\hline Observations & 509 & & & & & & \\
\hline \multicolumn{8}{|c|}{ Panel B: Non-exposed children 0-5 } \\
\hline Birth weight (kgs) & 3.46 & 0.26 & 2.60 & 3.00 & 3.50 & 3.60 & 4.30 \\
\hline Observations & 67 & & & & & & \\
\hline \multicolumn{8}{|c|}{ Panel C: Exposed children 8-15 } \\
\hline Raven's CPM & 0.76 & 0.31 & 0.42 & 0.67 & 0.83 & 0.92 & 1.00 \\
\hline Math score & 0.57 & 0.46 & 0.20 & 0.40 & 0.60 & 0.80 & 0.90 \\
\hline Observations & 1492 & & & & & & \\
\hline \multicolumn{8}{|c|}{ Panel D: Non-exposed children 8-15 } \\
\hline Raven's CPM & 0.79 & 0.26 & 0.50 & 0.67 & 0.83 & 0.92 & 1.00 \\
\hline Math scores & 0.61 & 0.41 & 0.30 & 0.40 & 0.60 & 0.80 & 0.90 \\
\hline Observations & 203 & & & & & & \\
\hline \multicolumn{8}{|c|}{ Panel E: Exposed adults 18-65 } \\
\hline $\begin{array}{l}\text { Hours worked (in } \\
\text { logs) }\end{array}$ & 3.67 & 0.15 & 3.05 & 3.56 & 3.81 & 4.03 & 4.25 \\
\hline Observations & 3671 & & & & & & \\
\hline Earnings (in logs) & 13.48 & 0.07 & 12.21 & 12.95 & 13.55 & 14.08 & 14.56 \\
\hline Observations & 3221 & & & & & & \\
\hline \multicolumn{8}{|c|}{ Panel F: Non-exposed adults 18-65 } \\
\hline $\begin{array}{l}\text { Hours worked (in } \\
\text { logs) }\end{array}$ & 3.71 & 0.15 & 3.05 & 3.56 & 3.87 & 4.03 & 4.25 \\
\hline Observations & 606 & & & & & & \\
\hline Earnings (in logs) & 13.56 & 0.07 & 12.61 & 13.06 & 13.55 & 14.22 & 14.65 \\
\hline Observations & 518 & & & & & & \\
\hline
\end{tabular}

For the test scores, we dropped 3 observations from math scores which were missing in Raven's CPM. We dropped those who averaged 3 weeks longer than the average pregnancy of 9 months for the samples in this table. CV refers to coefficient of variation (the ratio of standard deviation to the mean).

and underestimated the long-term consequences of in-utero shocks for females in the bottom part of the hours-worked distribution. Although the effects on earnings at the median $(-10.6 \%)$ were negative and greater than at the mean $(-4.2 \%)$, the effects on earnings at all the quantiles in the table were imprecise and not significantly different from zero.

\section{Males}

The estimates for birth weights were negative and largest in the bottom half of the distribution, with the relatively large (significant at $90 \%$ confidence level) effect of 0.372 $\mathrm{kg}$ at the $25 \mathrm{th}$ quantile. The mean and other quantile estimates were not precisely estimated. For boys $8-15$ years old, Raven's CPM was significantly reduced by $12.5 \%$ for those at the 10th quantile in contrast to mean effects of $-5.6 \%$, whereas math scores were reduced by $13.6 \%$ at the 10th quantile in contrast to mean effects of $-8.5 \%$. Those at the 50th-90th quantiles registered smaller and noisy estimates. For labour market outcomes, in contrast to adult women, men registered small and insignificant effects across the entire hours-worked distribution. However, the labour supply results masked effects on earnings for men that were $6.3 \%$ lower at the mean, with the largest effect of $-17.3 \%$ at the 10th quantile, though these are not statistically significant.

Even though tables 3 and 4 show mean and quantile estimates, they do not show if the difference between the mean effects and those reported in each quantiles was statistically significant. Online supplementary appendix table A2F and table A2M showed two-sided t-tests of differences between means and the quantiles for females and males, respectively that were mostly insignificant. To assess an alternate measure of central tendency, online supplementary appendix table A3F and table A3M showed differences between median and lower quantiles for females and males respectively. Table A3F most clearly shows that Raven's scores (Q25) and hours-worked (Q10) quantile estimates were significantly lower than 
Table 3 Impacts of Ramadan exposure in-utero- Muslim females

\begin{tabular}{lllllll}
\hline & Mean (OLS) & Q10 & Q25 & Q50 & Q75 & Q90 \\
\hline Birth weight & 0.143 & 0.237 & 0.007 & 0.243 & 0.100 & -0.320 \\
& $(-0.211,0.498)$ & $(-0.336,0.811)$ & $(-0.681,0.695)$ & $(-0.301,0.786)$ & $(-0.436,0.636)$ & $(-1.172,0.532)$ \\
Observations & 559 & & & & \\
Raven's CPM & -0.092 & -0.190 & -0.194 & -0.019 & -0.048 & -0.043 \\
& $(-0.150,-0.034)$ & $(-0.362,-0.017)$ & $(-0.286,-0.102)$ & $(-0.121,0.082)$ & $(-0.097,0.001)$ & $(-0.092,0.006)$ \\
& 1693 & & & & & \\
Math scores & -0.086 & -0.074 & -0.159 & 0.000 & 0.000 & -0.050 \\
\hline Observations & $(-0.158,-0.013)$ & $(-0.248,0.101)$ & $(-0.304,-0.015)$ & $(-0.123,0.123)$ & $(-0.121,0.121)$ & $(-0.157,0.056)$ \\
Hours worked & -0.075 & -0.263 & -0.137 & -0.029 & -0.002 & 0.003 \\
\hline Observations & $(-0.145,-0.016)$ & $(-0.475,-0.052)$ & $(-0.280,0.005)$ & $(-0.115,0.057)$ & $(-0.068,0.065)$ & $(-0.103,0.109)$ \\
Earnings & -0.042 & & & & & \\
\hline & $(-0.180,0.097)$ & $(-0.157,0.350)$ & $(-0.160,0.286)$ & $(-0.293,0.081)$ & $(-0.205,0.119)$ & $(-0.120,0.200)$ \\
\hline Observations & 2419 & & & & & \\
\hline
\end{tabular}

Two-sided 95\% robust confidence intervals in parentheses. Each cell presents a coefficient estimate on the exposure dummy defined in the main text. Sample for hours worked and earnings was restricted to positive values and to those aged 18-65 y in 2007, for test scores, 8-15 y olds in 2007, and for birth weight, retrospective data was used for those aged 0-5 y in 1993. Birth weights greater than $7 \mathrm{kgs}$ were dropped from sample (outliers probably due to measurement or recording errors).

the median estimates for females. Table A3M showed no significant differences between median estimates and lower quantiles for males.

We also carried out Wald tests to examine gender differences in the quantile estimates. Online supplementary appendix table A4 shows two-sided t-tests of mean differences between males and females. Perhaps the most striking contrast was that despite there being no clear precisely estimated female-male differences in birth weights or test scores due to Ramadan exposure, women in the bottom quantiles suffered disproportionally more in terms of reduced labour supply than men.

\begin{tabular}{|c|c|c|c|c|c|c|}
\hline & Mean (OLS) & Q10 & Q25 & Q50 & Q75 & Q90 \\
\hline \multirow[t]{2}{*}{ Birth weight } & -0.307 & -0.300 & -0.372 & -0.162 & 0.000 & -0.360 \\
\hline & $(-0.705,0.092)$ & $(-0.988,0.388)$ & $(-0.755,0.012)$ & $(-0.568,0.243)$ & $(-0.732,0.732)$ & $(-1.544,0.825)$ \\
\hline Observations & 624 & & & & & \\
\hline \multirow[t]{2}{*}{ Raven's CPM } & -0.056 & -0.125 & -0.083 & -0.037 & -0.009 & -0.010 \\
\hline & $(-0.109,-0.004)$ & $(-0.244,-0.006)$ & $(-0.171,0.005)$ & $(-0.095,0.021)$ & $(-0.065,0.048)$ & $(-0.050,0.031)$ \\
\hline Observations & 1821 & & & & & \\
\hline \multirow[t]{2}{*}{ Math scores } & -0.085 & -0.136 & 0.000 & -0.100 & -0.075 & 0.021 \\
\hline & $(-0.151,-0.019)$ & $(-0.261,-0.011)$ & $(-0.128,0.128)$ & $(-0.238,0.038)$ & $(-0.199,0.050)$ & $(-0.128,0.170)$ \\
\hline Observations & 1825 & & & & & \\
\hline \multirow[t]{2}{*}{ Hours worked } & -0.027 & 0.008 & 0.017 & 0.002 & -0.019 & -0.007 \\
\hline & $(-0.074,0.021)$ & $(-0.150,0.166)$ & $(-0.040,0.075)$ & $(-0.033,0.036)$ & $(-0.057,0.020)$ & $(-0.055,0.041)$ \\
\hline Observations & 4599 & & & & & \\
\hline \multirow[t]{2}{*}{ Earnings } & -0.063 & -0.173 & -0.033 & -0.028 & -0.033 & -0.062 \\
\hline & $(-0.154,0.028)$ & $(-0.446,0.099)$ & $(-0.160,0.094)$ & $(-0.128,0.073)$ & $(-0.167,0.101)$ & $(-0.222,0.098)$ \\
\hline Observations & 4019 & & & & & \\
\hline
\end{tabular}

Two-sided 95\% robust confidence intervals in parentheses. Each cell presents a coefficient estimate on the exposure dummy defined in the main text. The sample for hours worked and earnings was restricted to positive values and to those aged 18-65 y in 2007, for test scores, 8-15 y olds in 2007, and for birth weight, retrospective data was used or 0-5 y olds in 1993. Birth weights greater than $7 \mathrm{kgs}$ were dropped from sample (outliers probably due to measurement or recording errors). 
DISCUSSION

\section{Statement of principal findings}

This study explored the distributional consequences of prenatal malnutrition and stress (in the form of in-utero exposure to Ramadan) in Indonesia on birth weights, performance on Raven's progressive matrices, math scores, hours worked and earnings. Muslim boys exposed to Ramadan in-utero had generally lower birth weights, though the coefficients were not precisely estimated. Among school-age (8-15 years) children, the Raven's test scores and math skills of exposed boys and girls suffered, with most damage to those who scored lower relative to those who scored higher, increasing inequalities in learning. The learning deficiencies for the 'relatively poor' girls translated into lower labour supplies, especially for those working the least, without affecting men's labour supplies, hence further widening the gender gap in labour supplies. However, for men we found evidence (though imprecisely estimated) of reduced earnings especially for those who earned relatively little.

\section{Study strengths and weaknesses}

This was the first study to document the distributional consequences of fetal malnutrition and stress on birth weights, learning/cognition and adult labour supply/ hours worked and earnings, using Ramadan exposure in-utero as a natural experiment. This was also the first study to explore effects of Ramadan on earnings in Indonesia and the first to study gender-differentiated effects for all the outcomes considered.

Particular study strengths were the novelty and importance of our natural experiment, that is, exposure to the holy month of Ramadan during pregnancy, which allowed comparisons of outcomes of Muslims whose fetal period ad hoc happened to overlap with Ramadan, to those for whom there was no overlap with Ramadan. In the lunar Islamic calendar, every year Ramadan moves back 11 days, so that over a 33-year period, Ramadan covers all seasons, removing concerns about seasonality confounding our estimates. We further included month-of-birth fixed effects in our models, to address any remaining concerns about seasonality. Indonesia is on the equator so that it has 14 hours of daylight hours and relatively homogeneous temperatures throughout the year. This makes exposure to Ramadan as good as random, allowing us to make causal inference. Even if we were to consider a randomised control trail, due to ethical reasons, one could not randomly assign pregnant women to varying levels of Ramadan exposure, so our setting arguably offered the cleanest design possible to identify effects of prenatal nutritional deprivation and stress associated with in-utero Ramadan exposure that should be of value to the broader literature on developmental origins and development over long segments of the life cycle. ${ }^{9} 101218$ And for studying long-term effects in a new study one would have to wait for $40+$ years; in contrast, we presented findings over a long time horizon using rich longitudinal data from the IFLS.
IFLS has many strengths, including providing data on not just month of birth, but day of birth, which was critical for identifying exposure to Ramadan. The earnings data specially asked self-employed workers their earnings as well, thus allowing us to estimate effects on earnings for formal and informal employment. Other popular health surveys, like the Demographic and Health Surveys, did not collect data on cognition or labour supplies or earnings or days of birth for children or adults.

Our study had some weaknesses as well. We did not have data on conception dates, so we had to assume 266 days of pregnancy to estimate conception. One may be concerned that if pregnancy lasted longer than 9 months then those who were actually exposed may have been declared not exposed. Following Van Ewijk (2011) and Majid (2015), we controlled for all those who were conceived within 3 weeks after the end of Ramadan. On the other hand, if there were preterm births, we may have declared some individuals who were born preterm to be exposed to Ramadan who were actually not exposed. This could have also biased our estimates. However, it also possible that Ramadan itself led to preterm births. ${ }^{3}$

Another weakness of our study was that we did not have data on the channels through which exposure to Ramadan impacts life outcomes. For instance, Ramadan could have negative impact due to fasting choices made by mothers during pregnancy or it may be the case that these effects captured changes in sleeping patterns in Ramadan or changes in diet after breaking of fasts (oily and greasy foods) or stresses associated with the holidays. $^{15}$

Finally, birth weights were retrospectively reported by mothers. Mothers who may have been more severely impacted by Ramadan exposure during pregnancy might have more difficulty in recalling their children's birth weights. It is difficult to ascertain whether mothers would recall higher or lower values of birth weights depending on their own health. Hence, while systematic measurement error bias in birth weights cannot be ruled out, the direction of bias is unknown.

\section{Strengths and weaknesses compared with others}

We conducted a broad search in PubMED and EconLit for manuscripts published in any language from database inception to 15 September 2018, using the following search terms: 'fetal origins' OR 'Barker hypothesis' OR 'developmental origins' in PubMed and 'fetal' OR 'Barker' OR 'in utero' OR 'prenatal' in EconLit. The searches yielded more than 2000 papers but strikingly, less than $0.5 \%$ (10) studied distributional impacts of fetal environmental shocks (this included studies covering not just Ramadan, but also famines, alcohol, smoking and early-life economic adversities). One study examined the long-term distributional effects of fetal exposure to the Great Chinese Famine on adult hours worked, but was marred by concerns about selective mortality, possibly leading authors to find effects on the highest quantiles only. ${ }^{31}$ No effects on cognitive ability were reported. A 
recent study on alcohol availability in-utero in Sweden studied the distributional effects on earnings, but did not explore the effects on the outcomes that we investigated, such as the cognitive abilities of school-aged children and hours worked for adults. ${ }^{16}$ Hence, not much is known about the distributional impacts of fetal shocks, especially on economic performance. Further, evidence from middle-income countries remains scarce.

In contrast to most recent studies on the fetal origins hypothesis that examined the effects of famines as a natural experiment, this study identified the effects of a mild behavioural choice-daytime fasting and related stresses during pregnancy-which was more likely to be under the control of decision makers such as mothers and family members. This allowed us to obtain causal evidence on the fetal origins hypothesis since those exposed to Ramadan were less likely to suffer from mortality-related selection concerns that arise in famine studies, leading some studies to find rather confusing positive effects of famines on later-life outcomes. ${ }^{23} 36$ Indeed, we did not find any difference in cohort size by Ramadan exposure, thereby alleviating concerns about mortality-related selection biasing our estimates.

\section{Policy implications and conclusion}

Muslims have been celebrating the Islamic holy month of Ramadan, often by fasting, for more than 1400 years. Currently, more than 1.2 billion (of 1.6 billion) Muslims globally, and 155 million Indonesians were potentially exposed to fasting and other stresses during Ramadan when in-utero. The potential population affected is, thus, much larger than other "natural experiments' used in the literature to investigate the impacts of in-utero shocks: more than twice the roughly 500 million directly affected by the 1918 influenza pandemic and much larger than the roughly 5 million directly affected by the 1944 Dutch Famine. Although pregnant women are exempt from fasting in Islam, current evidence suggests that $70 \%-90 \%$ of pregnant women fast for at least some of Ramadan.

Currently, there is limited evidence on the effects of Ramadan on pregnant women and how it may affect future generations. Our study calls for more research on identifying the relevance of fasting during pregnancy in different contexts and developing an evidence base that can inform physicians, imams and families on what works best to manage health during Ramadan for pregnant women and what does not. The fact that Islam clearly exempts pregnant women from fasting suggests that this issue is not because of religious law per se but possibly because of ignorance and lack of coordination among doctors, imams, families and researchers on the nature and implications of this important risk factor affecting more than billion Muslims living around the globe today.

Policy interventions and efforts to mitigate the effects of Ramadan exposure in Indonesia should be targeted towards those with lower birth weights (for males), lower cognitive skills (girls and boys) and less labour force participation (for females) and less earnings (for men) rather than those who are better-off such as at the means who may be better able to take remedial measures or may in fact be less likely to have mothers who fasted or experienced holiday-related stress in the first place.

More broadly, our study highlighted the need to move beyond studying mean associations between fetal endowments and adult disease to more carefully assess the importance of the fetal environment (including nutrition and stress) in shaping the entire distributions of health and economic measures of well-being over distinct stages of the life course. This will allow policy makers to better target populations for whom the economic and non-economic returns of investing in nutrition and health are the highest. Such targeting will increase the effectiveness of the interventions and reduce inequalities and thus be 'win-win' policy solutions for Indonesia and other countries with similar concerns.

Contributors FM, JB and SM conceived of this study and general research strategy. FM undertook the data preparation and econometric estimates. JB and SM consulted with FM on the estimates and contributed to revisions in the estimates. FM wrote the first draft and JB and SM provided revisions. FM, JB and SM all read the final version and agreed that it was ready for submission. FM is guarantor.

Funding This research was supported by Grand Challenges Canada 'Savings Brains' grant (Grant 0072-03 to the Grantee, The Trustees of the University of Pennsylvania).

Disclaimer The funding agency played no role in the conduct of this research and the decision to submit this manuscript for publication.

Competing interests None declared.

Patient consent for publication Not required.

Provenance and peer review Not commissioned; externally peer reviewed.

Data availability statement No additional data are available. We will be happy to share data used in the anlaysis upon request.

Open access This is an open access article distributed in accordance with the Creative Commons Attribution Non Commercial (CC BY-NC 4.0) license, which permits others to distribute, remix, adapt, build upon this work non-commercially, and license their derivative works on different terms, provided the original work is properly cited, appropriate credit is given, any changes made indicated, and the use is non-commercial. See: http://creativecommons.org/licenses/by-nc/4.0/.

\section{REFERENCES}

1. Alderman $\mathrm{H}$, Behrman JR, Glewwe $\mathrm{P}$, et al. Evidence of impact of interventions on growth and development during early and middle childhood. Disease control priorities, (volume 8): child and adolescent health and development, 2017.

2. Almond D, Currie J, Duque V. Childhood circumstances and adult outcomes: act II. National Bureau of Economic Research, 2017.

3. Almond D, Mazumder B. Health capital and the prenatal environment: the effect of Ramadan observance during pregnancy. Am Econ J Appl Econ 2011;3:56-85.

4. Barker DJ. The fetal and infant origins of adult disease. BMJ 1990;301:1111.

5. Barker DJ. Fetal origins of coronary heart disease. Heart 1993;69:195-6.

6. Behrman JR, Rosenzweig MR. Returns to birthweight. Rev Econ Stat 2004;86:586-601.

7. Behrman JR, Rosenzweig MR, Taubman P. Endowments and the allocation of schooling in the family and in the marriage market: the twins experiment. J Polit Econ 1994;102:1131-74. 
8. Black SE, Devereux PJ, Salvanes KG. From the cradle to the labor market? The effect of birth weight on adult outcomes. Q J Econ 2007;122:409-39.

9. Branca F, Piwoz E, Schultink W, et al. Nutrition and health in women, children, and adolescent girls. BMJ 2015;351.

10. Chen J, Chen P, Bo T, et al. Cognitive and behavioral outcomes of intrauterine growth restriction school-age children. PEDIATRICS 2016;137.

11. van Ewijk R. Long-term health effects on the next generation of Ramadan fasting during pregnancy. J Health Econ 2011;30:1246-60.

12. Fleming TP, Watkins AJ, Velazquez MA, et al. Origins of lifetime health around the time of conception: causes and consequences. The Lancet 2018;391:1842-52.

13. Heckman JJ. Skill formation and the economics of investing in disadvantaged children. Science 2006;312:1900-2.

14. Liu X, Behrman JR, Stein AD, et al. Prenatal care and child growth and schooling in four low- and medium-income countries. Plos One 2017;12:e0171299.

15. Majid MF. The persistent effects of in utero nutrition shocks over the life cycle: evidence from Ramadan fasting. J Dev Econ 2015;117:48-57.

16. Nilsson JP, availability A. Prenatal conditions, and longterm economic outcomes. Journal of Political Economy 2017;125:1149-207.

17. Reynolds RM, Allan KM, Raja EA, et al. Maternal obesity during pregnancy and premature mortality from cardiovascular event in adult offspring: follow-up of 1323275 person years. BMJ 2013;347:f4539.

18. Victora CG, Adair L, Fall C, et al. Maternal and child undernutrition: consequences for adult health and human capital. The Lancet 2008;371:340-57.

19. Huxley R, Neil A, Collins R. Unravelling the fetal origins hypothesis: is there really an inverse association between birthweight and subsequent blood pressure? The Lancet 2002;360:659-65.

20. Kramer MS. Invited commentary: association between restricted fetal growth and adult chronic disease: is it causal? Is it important? Am J Epidemiol 2000;152:605-8.
21. Kuh D, Shlomo YB, eds. A life course approach to chronic disease epidemiology. Oxford University Press, 2004.

22. Delisle H. Programming of chronic disease by impaired fetal nutrition, evidence and implications for policy and intervention strategies. World Health Organization, 2002.

23. Li C, Lumey LH. Exposure to the Chinese famine of 1959-61 in early life and current health conditions: a systematic review and metaanalysis. The Lancet 2016;388.

24. Joosoph J, Abu J, Yu SL. A survey of fasting during pregnancy. Singapore Med J 2004;45:583-6.

25. Makki AM. Impact of Ramadan fasting on birth weight in 4 hospitals in Sana'a City, Yemen. Saudi Medical Journal 2002;23.

26. Jürges $H$. Ramadan fasting, sex-ratio at birth, and birth weight: no effects on Muslim infants born in Germany. Economics Letters 2015;137:13-16.

27. Kraemer S. The fragile male. BMJ 2000;321:1609-12.

28. Kruger DJ, Nesse RM. Sexual Selection and the Male:Female Mortality Ratio. Evolutionary Psychology 2004;2.

29. Basu A. Women's roles and the gender gap in health and survival. Women's Health in India: Risk and Vulnerability. M. Das Gupta and L. C. Chen. Bombay, Oxford University Press 1995.

30. Gupta MD. Selective discrimination against female children in rural punjab, India. Popul Dev Rev 1987;13:77-100.

31. King E, Mason A. Engendering development: through gender equality in rights, resources, and voice. The World Bank, 2001.

32. Rosenzweig MR, Schultz TP. Market opportunities, genetic endowments, and intrafamily resource distribution: child survival in rural India. The American Economic Review 1982;72:803-15.

33. Sen AK. "More Than 100 Million Women Are Missing.". New York Review of Books 1990;37:61-6.

34. Strauss J, Witoelar F, Sikoki B, et al. "The Fourth Wave of the Indonesian Family Life Survey (IFLS 4): Overview and Field Report", 2009WR-675/1-NIA/NICHD.

35. Koenker R, Hallock KF. Quantile regression. J Econ Perspect 2001;15:143-56.

36. Meng X, Qian N. The long term consequences of famine on survivors: evidence from a unique natural experiment using China's great famine. National Bureau of Economic Research, 2009. 